\title{
Os governos Roseana Sarney e Flávio Dino nas manchetes de 0 Estado do Maranhão'
}

\section{The governments of Roseana Sarney and Flávio Dino in the headlines of O Estado do Maranhão}

\author{
Li-Chang Shuen Cristina Silva Sousa \\ Universidade Federal do Maranhão (UFMA) \\ $<$ lichangshuen@gmail.com>
}

\section{RESUMO}

Neste artigo, apresentamos parte dos resultados da pesquisa "Governando contra as notícias: o primeiro ano do Governo Flávio Dino nas páginas de O Estado do Maranhão". Analisamos a mudança de paradigma enfrentada pelo jornal a partir da posse de um governador de oposição ao grupo Sarney. Analisamos as chamadas de capa publicadas em 2014 e 2015, governos de Roseana Sarney e Flávio Dino, respectivamente. A metodologia utilizada foi a combinação de análise de valência com análise textual. Concluímos que o jornal, apesar de seguir formalmente os critérios de noticiabilidade e valores-notícia em sua cobertura durante o mandato de Roseana, adotava um discurso jornalístico-publicitário, atuando como relações públicas das ações governamentais naquele período, especialmente em assuntos negativos para o governo. A partir da posse de Dino, o jornal passa a atuar no campo oposicionista e abandona completamente o discurso positivo, transformando sua cobertura em um exercício de jornalismo adversário e atuando como arena de diálogo entre as elites em disputa pela hegemonia no Maranhão.

Palavras-chave: Jornalismo Adversário. Política. Hegemonia.

\begin{abstract}
In this paper, we present partial results of the research entitled "Governando contra as notícias: o primeiro ano do Governo Flávio Dino nas páginas de O Estado do Maranhão" (Governing against the news: the first year of Flávio Dino' Government on the pages of $O$ Estado do Maranhão newspaper). We analyze the paradigmatic shift faced by the newspaper resulting by the inauguration of a governor who is a political opponent of the Sarney's group. We analyzed the cover headlines published in 2014 and 2015, last and first years of the governments of Roseana Sarney and Flávio Dino, respectively. The methodology adopted is a combination of valence analysis and textual analysis. We concluded that the newspaper, despite formally following newsworthiness and news values on its news coverage during Roseana's mandate, adopted a journalistic-publicity discourse, acting as public relations of the governmental actions in that period, especially in negative issues for the government. Since Dino's inauguration, the newspaper started to act in an oppositional field and completely abandoned the positive discourse, changing its coverage into an adversarial journalism exercise and acting as a dialogue arena for the elites involved in the struggles for hegemony in Maranhão.
\end{abstract}

Keywords: Adversarial Journalism. Politics. Hegemony.

\section{Introdução}

Este artigo é um dos produtos da pesquisa em andamento Governando contra as notícias: o primeiro ano do governo Flávio Dino nas páginas de O Estado do Maranhão. Os resultados apresentados aqui são preliminares para o eixo

1 Pesquisa financiada com recursos da Fundação de Amparo à Pesquisa e ao Desenvolvimento Científico e Tecnológico do Maranhão - FAPEMA. 
comparativo sobre a atuação do jornal no último ano do governo de Roseana Sarney e no primeiro do governo Flávio Dino, respectivamente 2014 e 2015. A princípio, a pesquisa não contemplava um eixo comparativo, mas, na medida em que a coleta e a análise de dados para 2015 avançavam, dúvidas surgiam e, para que pudessem ser adequadamente respondidas, sentimos a necessidade de empreender um estudo comparado. $O$ objetivo era entender a construção da narrativa do estado-problema que Dino administrava. A partir de uma leitura não científica do jornal, sabíamos que, durante o segundo governo Roseana (2009-2014), as notícias positivas e de exaltação do governo saltavam à vista do leitor. Esse conhecimento empírico, porém, não era suficiente para aclarar os questionamentos que se colocavam diante de um pesquisador.

Que tipo de narrativa positiva o jornal construiu no último ano do governo Roseana e como essa narrativa mudou junto com o mandatário do Palácio dos Leões? Que construções linguísticas encontrávamos em 2014 e que sumiram em 2015 e, por outro lado, quais delas não estavam presentes - ou estavam em quantidade reduzida - antes e que passaram a predominar a partir de 2015? Como a narrativa jornalística transitou do Maranhão como estado em que tudo dá certo (estado-ficção) para um estado à deriva (estado-problema)? São essas questões que procuramos enfrentar a partir da análise comparada entre o noticiário do último ano do governo Roseana e o primeiro do governo Dino.

O último ano do governo Roseana Sarney (PMDB) não teve 12 meses completos. A governadora deixou o cargo em 10 de dezembro de 2014, alegando problemas pessoais, e não passou a faixa ao governador eleito Flávio Dino (PCdoB). Por isso, a coleta de dados para 2014 compreende o período de $1^{\circ}$ de janeiro a 10 de dezembro. A segunda "Era" Roseana ${ }^{2}$ começou em 17 de abril de 2009, após o Tribunal Superior Eleitoral cassar o então governador Jackson Lago (PDT), eleito em 2006, por abuso de poder econômico nas eleições em que Roseana foi derrotada em segundo turno. Em 2010, ela foi reeleita.

A governadora não conseguiu fazer seu sucessor, mesmo com toda a máquina governamental e midiática empregada para tentar eleger o suplente de senador Lobão Filho (PMDB). O candidato da coligação PCdoB-PSDB, Flávio Dino, foi eleito em primeiro turno em 2014 com 63,52\% dos votos válidos. A oposição ao clã Sarney já havia ensaiado uma quebra de hegemonia ao eleger Jackson Lago em 2006, mas a aliança de então envolvia muitos ex-sarneysistas (como o ex-governador José Reinaldo Tavares, que era vice de Roseana e, já

2 A então deputada federal pelo PFL Roseana Sarney se elegeu para um primeiro mandato como governadora em 1994 e foi reeleita em 1998. Em 2002, elegeu-se senadora e disputou um novo mandato de governadora em 2006, quando foi derrotada nas urnas, mas assumiu o governo após a cassação do governador eleito Jackson Lago. 
governador, rompeu com a oligarquia após um imbróglio envolvendo Roseana e sua esposa ${ }^{3}$ ). Com a cassação de Lago, a oposição passa a se organizar em torno do então deputado federal Flávio Dino e uma aliança improvável do ponto de vista nacional - coligação PCdoB e PSDB - começa a tomar corpo e culmina com a eleição de Dino.

Esse movimento de realocação das elites políticas locais deu início também a uma mudança na forma de fazer jornalismo do principal conglomerado de mídia do Maranhão. O Sistema Mirante de Comunicação é composto por um jornal - O Estado do Maranhão - com tiragem diária de cerca de 10 mil exemplares, 16 mil na edição de fim de semana (desde 4 de março de 2016 existe uma edição única que circula aos sábados e domingos), um portal de internet com conteúdo próprio, emissoras de rádio AM e FM que cobrem 200 dos 217 municípios maranhenses e, ainda, uma estrutura de televisão com emissoras em São Luís, Imperatriz, Santa Inês, Açailândia e Timon, que geram conteúdo para retransmissoras que cobrem cerca de $98 \%$ do território estadual. É uma força midiática considerável.

A pesquisa Governando contra as notícias: o primeiro ano do governo Flávio Dino nas páginas de O Estado do Maranhão trabalha com o noticiário do jornal O Estado do Maranhão em sua versão impressa. Em que pesem o ainda alto índice de analfabetismo ${ }^{4}$ e a baixa circulação impressa do jornal, OEMA é o principal braço político do Sistema Mirante de Comunicação. A TV Mirante é filiada à Rede Globo e deve seguir princípios editoriais ditados pela cabeça de rede. O jornalismo da televisão tem menos espaço para ser político (embora o noticiário televisivo também seja político, com nuances mais leves). Já o jornal é completamente livre de amarras externas. A narrativa política elaborada pelo jornal é apropriada pelo noticiário da televisão (em menor intensidade) e pela cadeia de rádios (com maior intensidade e maior alcance, por ser a mídia que mais se aproxima de seu público - que não precisa saber ler para ter acesso a ele).

O artigo está organizado em quatro partes, além da introdução e das considerações finais. Primeiro, apresentamos um detalhamento da metodologia utilizada. Na segunda seção, discutimos o jornalismo como agente político e espaço de disputa hegemônica. Em seguida, analisamos a construção narrativa

3 O motivo de fundo está no gigantismo da aliança/campo político nucleada por Sarney e em sua incapacidade de, em um momento de crise e desgaste dessa aliança após anos de exercício do poder, contemplar a todos. E no oportunismo de alguns líderes da aliança, que resolveram se posicionar melhor já para o próximo ciclo político, o qual, pensava-se, seria liderado por Jackson, e acabou sendo por Dino. Zé Reinaldo foi apenas a primeira dissidência. Outros desgarrados surgiriam com a crise do bloco no poder, e alguns deles hoje posicionam-se ao lado do governo Dino. 4 Taxa de $18,8 \%$ de analfabetismo e de $28,8 \%$ de analfabetismo funcional para a população maior de 15 anos, segundo dados de 2015 do IBGE. 
daquilo que chamamos de estado-ficção, durante o último ano do governo Roseana Sarney. Não apenas questões jornalísticas são levadas em consideração, mas também elementos do contexto político do estado. O mesmo se dá na seção seguinte, quando analisamos o momento em que o jornal passa a lidar com a necessidade de fazer, ao mesmo tempo, política de oposição ao governo Dino e jornalismo desvinculado do serviço de relações públicas que se via presente durante a Era Roseana.

\section{Notas metodológicas}

O estudo comparativo tem como base as edições de $O$ Estado do Maranhão de $1^{\circ}$ de janeiro a 10 de dezembro de 2014 e de $1^{\circ}$ de janeiro a 31 de dezembro de 2015. Como citado na introdução, foram contabilizadas as edições até o dia 10 de dezembro de 2014 porque, naquela data, alegando questões pessoais, Roseana Sarney renunciou ao cargo. Optamos por não contabilizar as chamadas dessa data em diante porque a mudança da protagonista poderia impactar de forma imprevisível no comportamento das variáveis linguísticas a serem analisadas.

O primeiro passo foi catalogar as valências ${ }^{5}$ de todas as chamadas de capa para os dois anos que tivessem o governo do Estado, a governadora/o governador, ou as secretarias/áreas de atuação como protagonistas. Em 2014, 581 chamadas atenderam ao critério estabelecido. Em 2015, foram 795. As chamadas foram divididas por tema: Segurança, Saúde, Educação, Economia, Política e Infraestrutura. Após a catalogação das valências, seguimos para a segunda etapa de tratamento dos dados: escolher 28 capas para, então, selecionar os textos que seriam processados no software de análise linguística Iramuteq ${ }^{6}$. Essa etapa foi de trabalho manual. Primeiro, catalogamos todas as edições por dia da semana: todas as edições de segundas, terças, quartas etc.

O passo seguinte foi sortear, de maneira aleatória no próprio Excel, quatro edições de segunda, quatro edições de terça, e assim por diante, até que obtivéssemos 28 edições, formando aproximadamente um mês. Optamos pelo mês lunar, de 28 dias, em vez do mês de 30 ou 31 dias por questão de padronização: queríamos exatamente quatro edições de cada um dos dias da semana, de forma a evitar qualquer distorção por ter uma segunda-feira a mais, por exemplo. A amostra bruta de capas teve então 28 edições para 2014 e 28

5 Catalogar as valências consiste em determinar se as notícias possuem viés positivo, negativo ou neutro em relação a um assunto ou personagem.

6 Iramuteq é um programa de análise linguística que nos permite produzir gráficos, nuvens de palavras e contagem de termos mais usados em um texto ou conjunto de textos, além de outras funcionalidades. 
edições para 2015. Após essa etapa, todas as chamadas que atendiam ao critério de seleção foram catalogadas. Chegamos assim a um total de 44 textos para 2014 e 50 para 2015. Esse seria o universo de análise textual a ser processado no Iramuteq. Os textos foram processados em dois arquivos diferentes, um para cada ano. As linhas de comando para cada chamada digitada no Open Office ${ }^{7}$ atendiam ao padrão: número do texto, valência e tema.

Os resultados que discutimos nas seções a seguir, então, combinam o olhar que a análise de valências permite lançar sobre o tratamento quantitativo de dois governos sob a perspectiva de um mesmo jornal, uma análise textual de ocorrências e correlações linguísticas feita pelo software, e uma análise qualitativa feita a partir de um olhar crítico sobre as narrativas que formatam o discurso de $O$ Estado do Maranhão sobre o governo do Estado em duas administrações diferentes. Restringimos a análise final a esse universo de 94 chamadas para que o processo de análise qualitativa fosse exequível. Afinal, softwares conseguem registrar padrões e tendências, mas não conseguem ainda extrair as relações políticas que uma notícia estabelece com as elites com as quais os meios de comunicação dialogam.

\section{Jornalismo, discurso e poder}

O jornalismo não é apenas um conjunto de técnicas de recolha, processamento e publicização de fatos transformados em notícia. $O$ jornalismo é, fundamentalmente, uma atividade política (Gramsci, 2006). A técnica, que promete objetividade e imparcialidade, apenas legitima visões de mundo de quem faz a mediação entre o fato e o público que consome notícias, visões estas influenciadas por questões pessoais, socioculturais e organizacionais (Schudson, 1978). Em seus estudos, Sousa (2002) aponta ainda que, além dos fatores apontados por Schudson, a notícia é uma construção influenciada por fatores ideológicos, históricos e tecnológicos.

As notícias são um artefato cultural, pois elas ajudam a criar mundos possíveis (Alsina, 1996), por meio da seleção e do enquadramento que os jornalistas emprestam aos acontecimentos. Também são artefatos políticos (Sparrow, 1999; Thompson, 2002; Genro Filho, 1987), posto que "a mídia não se limita a difundir, ela também transforma o discurso político" (Miguel, 2002, p.14). Ao estudar jornais impressos em uma era dominada pelas mídias digitais, assumimos que os jornais impressos são, no Brasil, canais nos quais flui o diálogo

7 Os textos precisam estar em arquivos do Open Office para que o Iramuteq consiga processá-los corretamente. 
entre as elites políticas. A cobertura política na imprensa é, antes de tudo, uma espécie de mediação entre elites.

Sem menosprezar a tradição funcionalista que concebe o jornalismo como atividade que tem funções sociais a cumprir, adotamos a perspectiva de que o jornalismo não é um mero vigilante do meio, mas uma instituição política que não é substancialmente diferente das demais instituições políticas em sociedades democráticas (Sparrow, 1999; Cook, 2005). Como tal, a mídia em geral - e o jornalismo em particular - é um ator político cuja relevância não deve ser ignorada, posto que seu discurso é "situado e marcado por uma rede complexa de relações" (Miguel e Biroli, 2010, p. 66). O jornalismo, porque perpassado pela política, é inseparável dela.

A observação de em relação à atuação política da imprensa nacional é ainda mais aguda se pensarmos no jornalismo regional:

Após longo processo histórico de autonomização do "campo" jornalístico brasileiro - processo que se acelerou na segunda metade do século passado [...] - os seus mais influentes e prestigiosos veículos impressos simplesmente retrocederam, há coisa de uma década, a um comportamento editorial que pode, sem maiores riscos, ser classificado como partidário (Lattman-Weltman e Chagas, 2016, p. 325).

O texto jornalístico de cunho político é um modo de ação. É também um discurso. Adotamos o conceito de Fairclough, para quem "discurso é uma forma em que as pessoas podem agir sobre o mundo e especialmente sobre os outros, como também um modo de representação" (Fairclough, 2001, p. 91). Enquanto discurso, a notícia é ideológica, jamais neutra, jamais objetiva. A partir de uma perspectiva crítica, não é possível pensar o jornalismo apenas como um aparato social que cumpre funções na sociedade, mas como uma instituição política, que age de acordo com interesses específicos e algumas vezes contraditórios (Cook, 2005; Esser, Strömbäck, 2014; Graber, Macquail, Norris, 2008). A atividade jornalística como exercício político e a notícia como produto político podem ser classificados como produção de sentido a serviço do poder e da dominação, ou seja, é ideologia na acepção que Wolf (1999; 2003) dá à palavra.

Outra vez recorremos a Lattman-Weltman e Chagas para compreender que o mercado da mídia é composto pelos mercados da troca de informações, de publicidade comercial e pelo mercado de discursos públicos. Segundo os autores, 
toda possível neutralidade, assim como todo viés, é função do contexto em que se dá não somente a efetividade da informação, mas também quaisquer outras (re)apropriações da mesma. Daí a natureza intrinsecamente política da instituição (a despeito de sua autonomização como negócio) (Lattman-Weltman e Chagas, 2016, p. 327).

Se o discurso, por definição, é ideológico, e a notícia é um texto que expõe a superfície de um discurso, a notícia é um produto político-ideológico por excelência, não importando se a pauta é da área de polícia, esporte, entretenimento ou poder. $O$ mito da objetividade e da imparcialidade, cânones do jornalismo moderno desenvolvido a partir da segunda metade do século XIX, escondeem seus fundamentos o fato de queo objeto da notícia, o acontecimento, é selecionado para ser publicizado a partir de uma série de critérios objetivos apenas em sua aparência. Ao separar o fato da opinião e ao criar uma nova categoria profissional (os jornalistas), o jornalismo contemporâneo estaria apto a "retratar" o mundo de forma fiel. A Teoria do Espelho, primeira a tentar explicar por que as notícias são como são, tem na força de seu modelo explicativo a sua maior fragilidade (Traquina, 2004). Afinal, a notícia não é o espelho de qualquer realidade, mas um recorte dela. Esse recorte é um artefato cultural - algumas notícias só são notícias em determinados contextos históricos e sociais - e também político,com umfortecomponenteeconômicoa perpassarsua estrutura.

A notícia é, em realidade, uma construção (Tuchman, 1983; Traquina, 2004; Gans: 1980; dentre outros). Há interesses a serem atendidos ao escolherse publicizar um acontecimento em vez de outro. Há ideologias sendo propagadas ao escolher-se uma palavra e não outra para descrever um fato. Pesquisas que confrontam a forma como um jornal noticia ações de diferentes governos conseguem dialogar com essa construção ao interpelar as palavras e expressões utilizadas em seus textos. As narrativas que encontramos nesta pesquisa apoiam-se na estrutura binária e simplista do estado-ficção versus estado-problema, governadora-trabalhadora versus governador-incompetente.

Parte da explicação é óbvia: a governadora é dona do jornal, o governador é o maior adversário político do grupo da qual ela faz parte. Mas mesmo o óbvio esconde sutilezas que necessitam de investigações mais aprofundadas. É impossível não lembrar a importância que Schudson (1998), Traquina (2004), Tuchman (1983), dentre outros, dão ao componente organizacional para explicar porque as notícias são como são, assim como de Gramsci (2006), para quem o contexto político dá forma ao jornalismo e a seu produto, a notícia. 
O Brasil tem uma tradição de estudos em que se aponta a monopolização da propriedade dos meios de comunicação como uma ameaça ao ideal democrático. Aocruzarmosos dados de propriedade dos meios com os resultados eleitorais, percebemos o quanto a mídia é importante para a manutenção de grupos no poder. Os dados para o Maranhão servem de exemplo. Em 2012, dos 2017 prefeitos eleitos no estado, 167 foram eleitos com o apoio do grupo Sarney, dentre os quais 47 do PMDB. Eleger prefeitos é importante para o grupo porque as eleições para deputados e governador dependem da máquina que esses prefeitos movimentam. Em 2014, a coligação que tentou eleger Lobão Filho como sucessor de Roseana Sarney elegeu 16 deputados estaduais. Nas eleições de 2016, o grupo perdeu a hegemonia nas prefeituras, pois o governador Flávio Dino conseguiu que 150 aliados se elegessem, 46 deles filiados ao seu partido, 0 PCdoB (contra 22 do PMDB). O recuo do grupo Sarney nas prefeituras aumentou a crise financeira ${ }^{8}$ do Sistema Mirante, que perdeu uma fonte importante de financiamento - a publicidade governamental. É um circuito que se fechava em si mesmo e que, agora, está ameaçado pela ascensão de outro grupo ao poder.

\section{O estado-ficção: jornalismo-relações públicas}

O poder da mídia é de natureza linguística e discursiva (Fairclough, 1995). Como o mundo é representado, que identidades são estabelecidas, que relações são construídas entre os personagens de uma história, que palavras e expressões são utilizadas para se referir a pessoas e eventos: são questionamentos que ajudam a lançar um olhar sobre o mundo possível que o jornalismo entrega ao seu público. As palavras têm uma vida social e política que se nutre da relação entre elas, seus sujeitos e seus objetos. Nesta parte do paper, apresentamos os resultados para 2014 da cobertura de O Estado do Maranhão sobre temas afeitos ao governo do estado. Os resultados serão apresentados na seguinte ordem: quadros e gráficos quantitativos relativos às valências das 581 chamadas de capa, gráfico com a análise de similitude feita pelo Iramuteq dos termos utilizados nas 44 chamadas que compõem o corpus analítico, relação das palavras mais utilizadas nesses textos e análise do contexto político-discursivo em que essas

8 Na última semana de março de 2017, o Sistema Mirante de Comunicação demitiu cerca de 70 profissionais, dentre jornalistas, técnicos e administrativos. A redação do jornal concentrou a maior parte dos cortes. De acordo com dados levantados junto a fontes ligadas ao mercado de mídia no estado, o jornal opera atualmente com um déficit de $\mathrm{R} \$ 700$ mil mensais. Esse dado, porém, não pôde ser confirmado no próprio sistema, que não divulga sequer a audiência global de O Estado do Maranhão (circulação impressa mais acessos ao portal). 
chamadas foram possíveis de produção dentro da lógica do jornal O Estado do Maranhão9.

O gráfico 1 apresenta um panorama da cobertura do jornal durante o último ano do governo de Roseana Sarney e é ilustrativo de como temas afeitos ao governo são um importante catalisador de pautas.

\section{Gráfico 1: Valências das chamadas de capa sobre ações do governo do Maranhão para 2014}

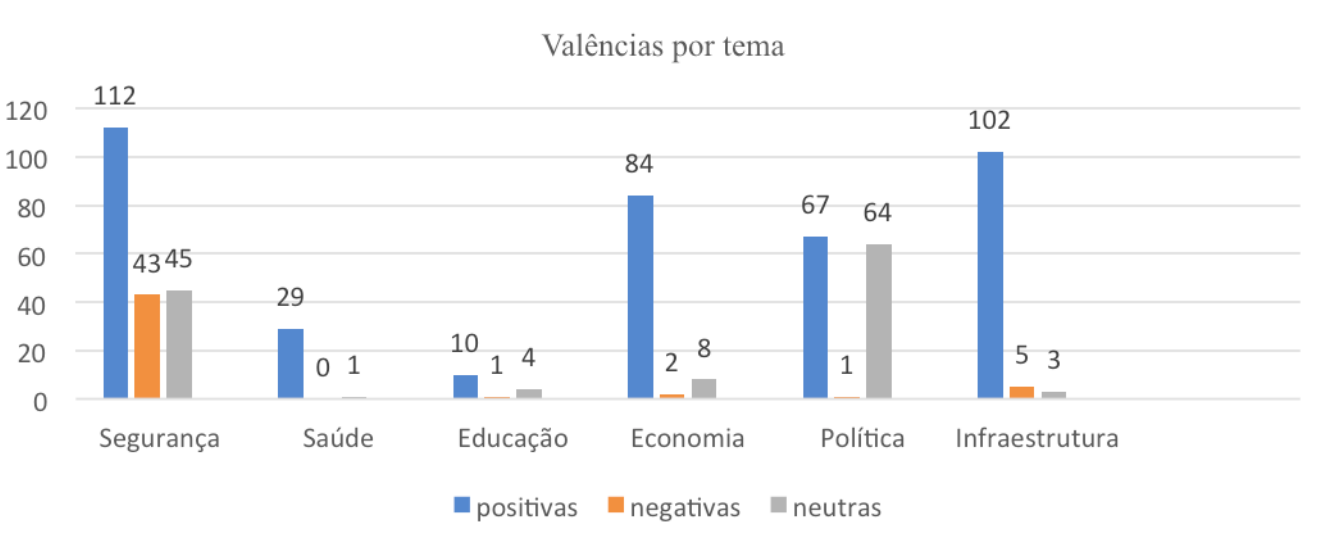

Fonte: elaboração do autor a partir de dados processados no Excel

O segundo gráfico mostra a tendência de cobertura ao longo dos meses.

\section{Gráfico 2: Valências das chamadas de capa mês a mês/2014}

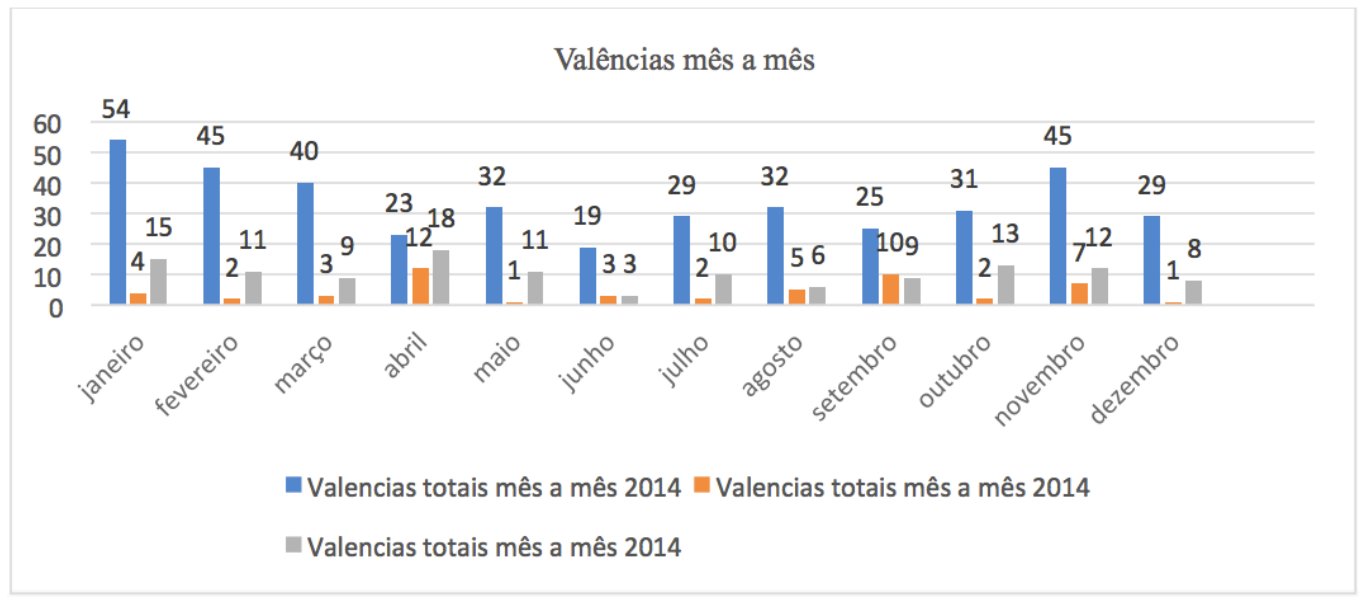

Fonte: elaboração do autor a partir de dados processados no Excel

9 A mesma sequência é utilizada na parte do paper referente ao noticiário no governo Flávio Dino. 
Ao todo, foram publicadas 581 chamadas de capa sobre assuntos concernentes ao governo estadual. O peso do tema "segurança" na amostra é contextual. O ano de 2014 foi marcado pelo caos no sistema penitenciário do Maranhão. A crise de Pedrinhas ${ }^{10}$, como foi retrancada pela mídia, atingiu em cheio a narrativa por nós classificada como de estado-ficção que era tecida pelo jornalismo do Sistema Mirante. Não era possível ignorar as rebeliões dentro do presídio, as decapitações, a onda de violência que se espalhou pela capital do estado a mando dos presidiários e, ápice da tragédia, a morte de uma garota de dez anos de idade durante um ataque incendiário a ônibus na cidade. As notícias negativas se referem aos fatos impossíveis de maquiar.

Então, como explicar que o número de chamadas positivasé maior do queo dobro das negativas? O jornalismo-relações públicas colocou suas engrenagens para funcionar e a rotativa do jornal passou a imprimir notícias de exaltação às ações ditas preventivas da Polícia Militar, do gabinete de segurança e da própria governadora, em parceria com o governo federal e instituições do Judiciário. A narrativa da segurança pública durante o ano de 2014 seguiu o esquema: choque com a realidade (notícias publicadas com menos filtros atenuantes, portanto negativas) - adequação da realidade (notícias que tentavam mostrar os problemas sem alarmismo, tendendo à neutralidade) - reação à realidade (notícias sobre acertos das forças estaduais de segurança, sempre positivas e publicitárias).

Chamadas como as reproduzidas no quadro a seguir mostram a tentativa de construir uma narrativa positiva para a segurança pública, apesar da crise do sistema carcerário:

Tabela 1: Amostra de chamadas sobre o tema da segurança pública/2014

\begin{tabular}{|c|c|l|}
\hline Edição & Data & Chamada (com título, subtítulos e texto complementar, quando houve) \\
\hline 18.790 & 23.01 .14 & $\begin{array}{l}\text { PM ocupará bairros com alto índice de criminalidade em São Luís. Operação } \\
\text { tem o objetivo de prender traficantes e homicidas, apreender armamentos } \\
\text { e drogas e desarticular facções criminosas. Polícia Civil indicia 16 pessoas, } \\
\text { quatro delas adolescentes, pela morte de Ana Clara em ataque a ônibus. }\end{array}$ \\
\hline
\end{tabular}

10 Em janeiro de 2014, uma série de rebeliões irrompeu no sistema penitenciário do Maranhão. O que começou com guerra entre facções dentro do presídio de Pedrinhas, na capital, São Luís, transformouse em uma crise de segurança pública que atingiu a população de forma violenta, com incêndio de ônibus, arrastões, depredações e assassinatos dentro e fora dos presídios, e culminou com a morte de uma garota de 10 anos em um ataque incendiário a um coletivo. Foi necessária a ajuda da Força Nacional para conter o problema. 


\begin{tabular}{|c|c|l|}
\hline 18.795 & 28.01 .14 & $\begin{array}{l}\text { Bope maranhense entrará em ação no mês de fevereiro. Homens de bata- } \\
\text { Ihão da Polícia Militar semelhante ao Bope do Rio de Janeiro iniciaram on- } \\
\text { tem, em São Luís, curso de formação para trabalhar no combate ao crime } \\
\text { organizado e ao tráfico de drogas em São Luís. 52 é o número de policiais } \\
\text { militares inscritos em grupamento especial. }\end{array}$ \\
\hline 18.817 & 19.02 .14 & $\begin{array}{l}\text { Caçada a ladrões de celular mobiliza até GTA. Adolescente assaltada no Be- } \\
\text { quimão acionou a polícia; coincidentemente, policiais rondavam o local. } \\
\text { Um dos suspeitos foi preso e outro conseguiu fugir. }\end{array}$ \\
\hline 18.837 & 11.03 .14 & $\begin{array}{l}\text { Dois planos de fuga são frustrados em presídios de São Luís. Detentos te- } \\
\text { riam serrado as grades das celas da unidade de ressocialização do Olho } \\
\text { D'Água e túnel chegou a ser escavado no CDP de Pedrinhas. }\end{array}$ \\
\hline 18.843 & 17.03 .14 & $\begin{array}{l}\text { Governo vai construir 19 delegacias no Maranhão. Oito delegacias de Po- } \\
\text { lícia Civil de São Luís e mais 11 regionais terão prédios novos; pacote de } \\
\text { obras da Secretaria de Segurança inclui ainda reforma de distrito e ingresso } \\
\text { de 2,5 mil novos profissionais ao sistema. }\end{array}$ \\
\hline
\end{tabular}

Fonte: capas de O Estado do Maranhão em 2014

As chamadas denotam uma narrativa condizente com um governo proativo, que se antecipa aos acontecimentos. As notícias possuem estrutura de anúncio publicitário. A segurança pública deixa de ser uma pauta de acontecimentos passados para ser pauta de acontecimentos futuros nos quais o governo estadual é o protagonista. É uma estratégia que se repete durante todo o ano de 2014, não apenas no auge da crise envolvendo os detentos da penitenciária de Pedrinhas. Afinal, o potencial negativo dessa área para o projeto de eleger o sucessor de Roseana Sarney precisava ser minimizado.

O segundo tema com o maior número de chamadas é o da infraestrutura. Por ser o último ano do mandato de Roseana, muitas obras foram inauguradas em todo o estado. E essas inaugurações eram noticiadas duas vezes: no dia da entrega da obra, para informar um acontecimento que iria ocorrer no dia, e na edição seguinte, com as fotos, as falas, a pompa da inauguração. Assim, Roseana foi associada à figura de empreendedora, com uma narrativa desenvolvimentista. O gráfico de similitude apresentado a seguir é ilustrativo. 
— Gráfico 3: Análise de similitude produzido pelo Iramuteq

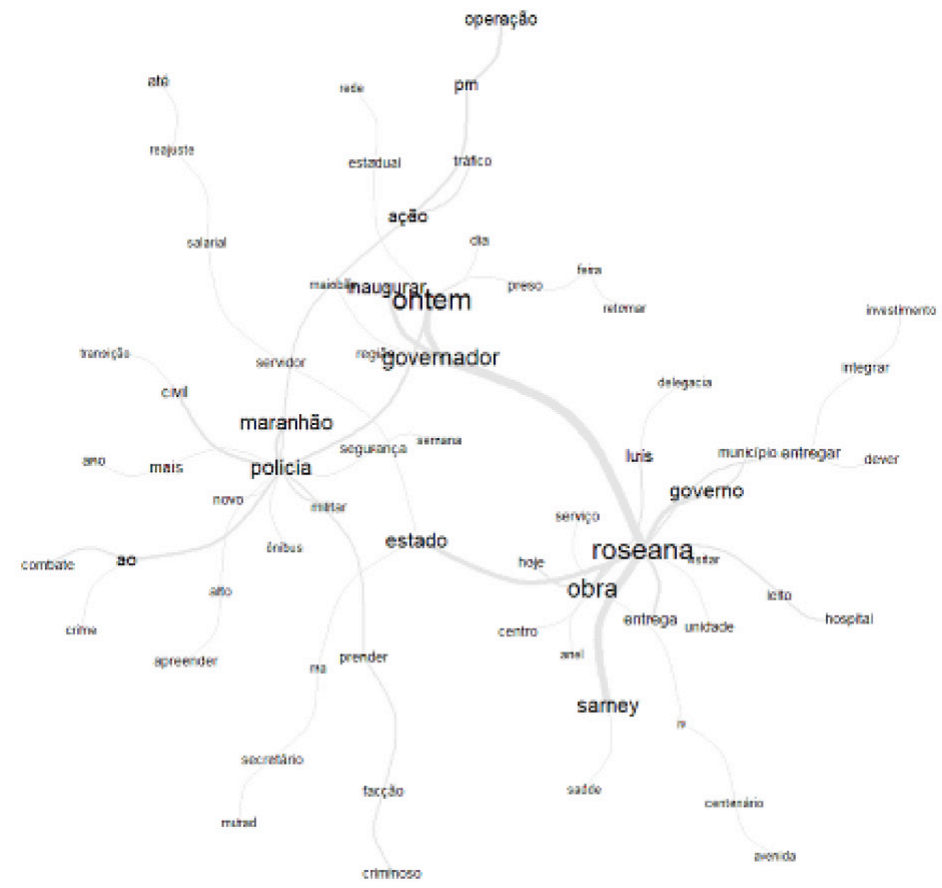

Fonte: elaboração da autora a partir das chamadas de capa processadas no Iramuteq

As palavras "Roseana" e "obra" aparecem, cada uma, 19 vezes na amostra de chamadas sob análise. São as duas palavras com o maior número de ocorrências. As palavras relacionadas "inaugurar", "entregar", "novo" e "entrega" aparecem, respectivamente, nove, seis, cinco e cinco vezes. $O$ jornal construiu uma narrativa que diz ao leitor que o último ano do governo Roseana foi marcado pelo desenvolvimento do estado com ênfase em infraestrutura. A narrativa é do estado em que tudo dá certo. Temos mais hospitais, mais escolas, mais capacidade portuária, mais delegacias, mais policiais nas ruas: estabelecese com esse discurso a pauta para comparação com o futuro governo. Não por acaso, a figura da Roseana empreendedora foi ressaltada com mais ênfase após o resultado das eleições.

Em 2014, Roseana aparece em 63 capas. Em termos de comparação, Flávio Dino é citado em apenas sete capas de 2015, apenas uma com foto. Há um superdimensionamento da figura da governadora. Em notícias positivas, o agente é sempre Roseana, Governadora, ou Governadora Roseana Sarney. Em notícias com valências negativas, o agente é abstrato: o governo do Estado. Há um movimento narrativo de associação entre o que é positivo à ação pessoal e o que é negativo à omissão institucional, de um ente não corpóreo, impessoal e que não pode ser reduzido a uma única pessoa. Afinal, Roseana é uma; governo 
do Estado é Roseana e seus auxiliares, os auxiliares destes e toda uma miríade de servidores públicos não identificados na narrativa jornalística.

O estado-problema: enfim, jornalismo?

O jornalismo adversário, segundo Guazina (2011), é uma forma de buscar credibilidade, autoridade e legitimidade para um veículo de comunicação. $A$ cobertura adversária "se caracteriza por ter como finalidade principal legitimar o próprio jornalismo como um poder e ator fundamental da cena pública. Tal cobertura baseia-se na oposição entre os campos jornalístico e político, através da desqualificação intensa da política, seus principais atores e instituições representativas" (Guazina, 2011, p.19).

No caso de $O$ Estado do Maranhão, o jornalismo adversário praticado a partir de 2015 é um reposicionamento editorial. Não foi uma escolha: foi uma imposição da realidade política moldada com o resultado da eleição de outubro de 2014. O jornalismo-relações públicas cedeu espaço para a prática de um jornalismo cão de guarda. O jornalismo político praticado por OEMA é um tipo de jornalismo adversário primitivo, no sentido de se assemelhar àquele praticado por jornais do século XIX - assumidamente alinhados a uma causa ou figura pública, ou assumidamente contrários a uma causa ou figura pública. Segundo nos mostra Couto (2009), o próprio José Sarney confirma a necessidade política de inserir-se no campo da mídia para divulgar tanto suas ideias e ações como as de seus aliados.

A abordagem negativa do governo Dino é, também, uma estratégia de exaltação do Maranhão "anterior". Os gráficos a seguir permitem visualizar, em números, a mudança de enfoque operada pelo jornal em 12 meses.

\section{Gráfico 4: Valências das chamadas de capa sobre ações do governo do Maranhão para 2015}

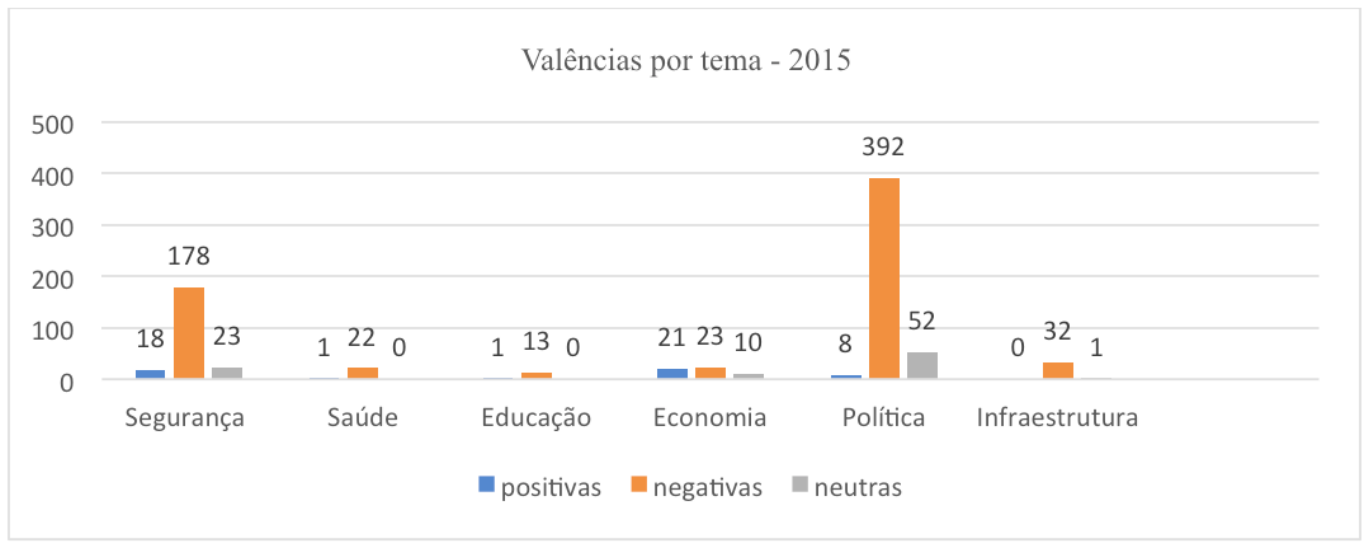

Fonte: elaboração da autora a partir de dados processados no Excel 
Atenderam aos critérios estabelecidos nesta pesquisa 795 chamadas em 2015. Quantitativamente, o primeiro ano do governo Flávio Dino esteve mais presente na capa do jornal do que o último do governo Roseana. Estar mais presente nas chamadas não significou, porém, abordagem mais favorável. Chama atenção a quantidade de chamadas negativas: $83 \%$ do total. O gráfico a seguir mostra a evolução da cobertura negativa ao longo dos meses.

\section{Gráfico 5: Valências das chamadas de capa mês a mês/2015}

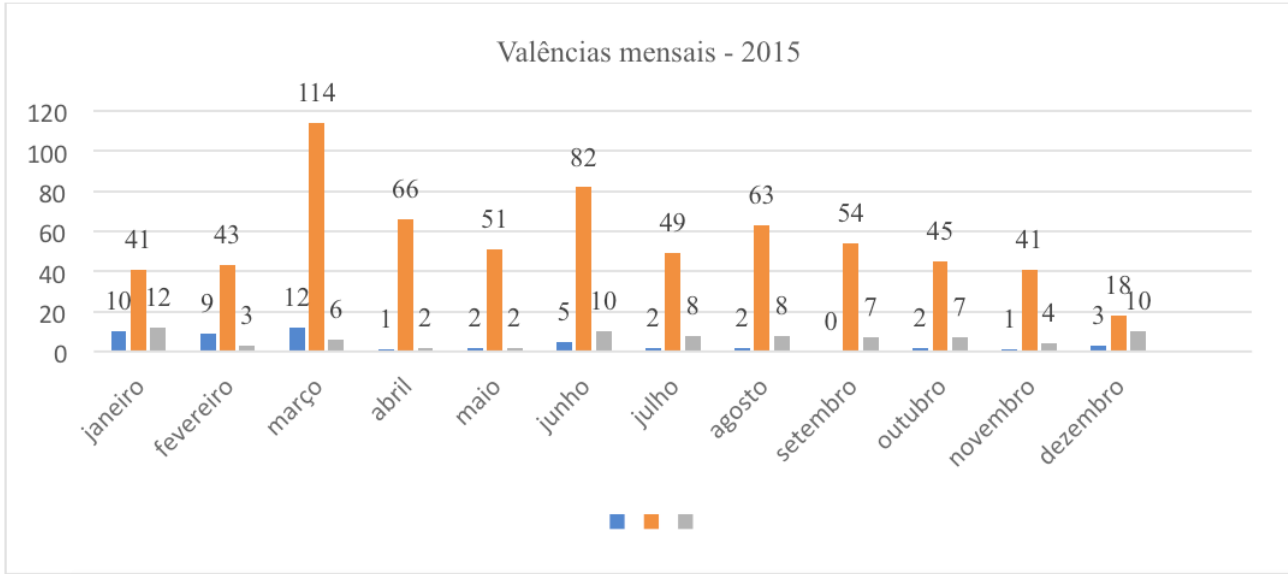

Fonte: elaboração da autora a partir de dados processados no Excel

Estes gráficos nos ajudam a compreender a intensidade do jornalismo adversário praticado pelo jornal. Em um ano, não haver uma única chamada positiva em relação à infraestrutura revela um contraste de perfis construído pelo jornal. Em 2014, houve 102 chamadas positivas nesse tema, o que ajudava a construir a imagem de Roseana Sarney como empreendedora em um estado cujo governo estava preocupado com o desenvolvimento de suas estruturas. Em 2015, houve um salto em chamadas negativas sobre infraestrutura: aparentemente, o jornal descobriu que o Maranhão não era um lugar perfeito, as estradas não eram boas o bastante, faltavam hospitais e escolas etc.

Quando somos confrontados com esses dados comparativos, percebemos que a cobertura negativa é muito mais do que a quantidade de chamadas: ela é, em si, a própria narrativa e o discurso. É política. Por fim, o gráfico de similitude para 2015: não há obras, não há empreendedorismo, falta segurança e sobram críticas à atuação do governador. É o retrato de um momento construído discursivamente no qual o Maranhão ficou pior. 
Gráfico 6: Análise de similitude produzido pelo Iramuteq

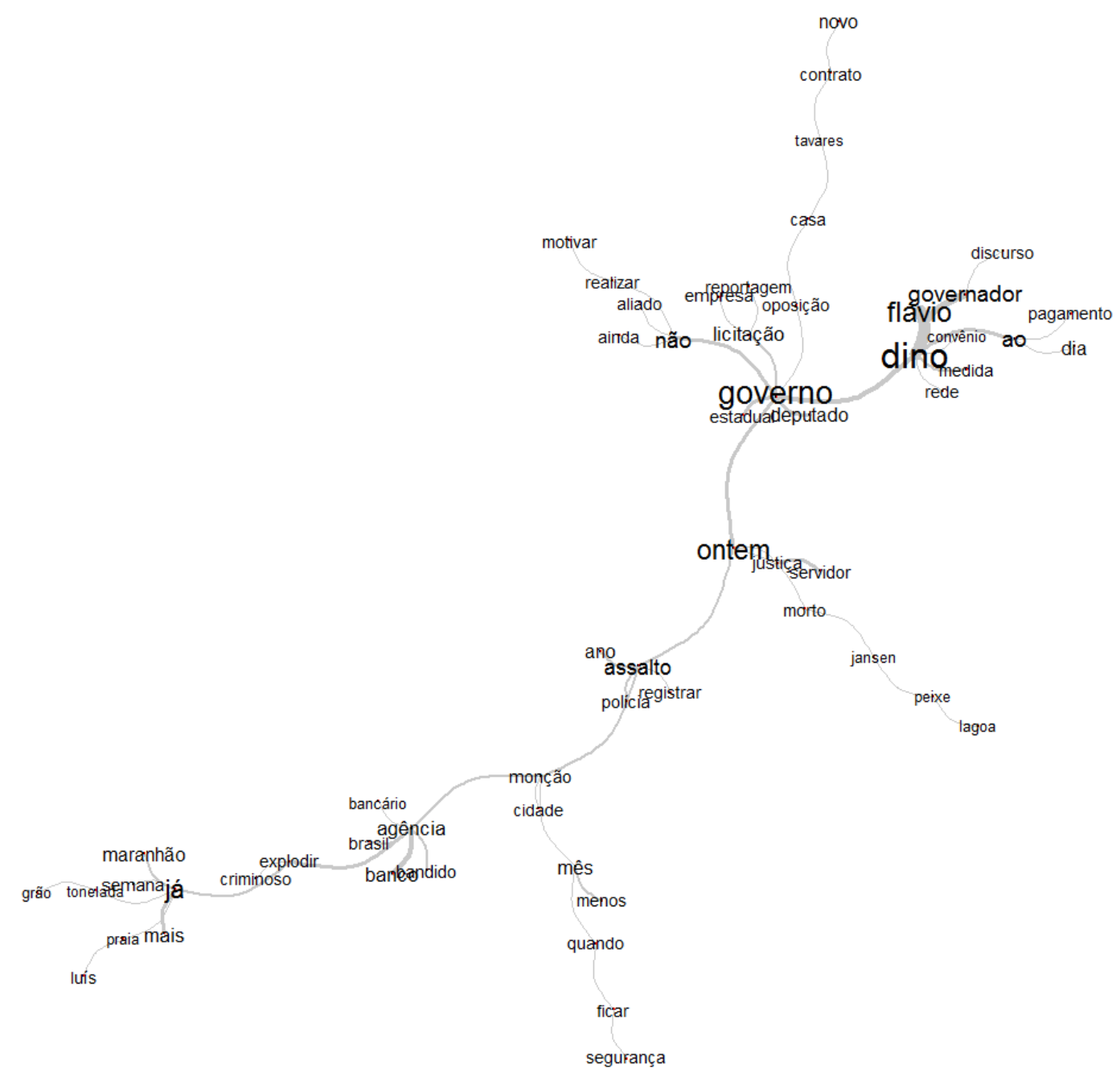

Fonte: elaboração da autora a partir das chamadas de capa processadas no Iramuteq

Os três termos mais utilizados nas 50 chamadas analisadas foram Dino, Governo e Flávio, grafados respectivamente 20, 17 e 12 vezes. Governador aparece oito vezes. As demais palavras mais usadas são referentes ao vocabulário da segurança pública: assalto (oito vezes), explodir (seis vezes) e morto (cinco vezes). Assim como há um superdimensionamento positivo para o nome de Roseana em 2014, há um superdimensionamento negativo para Dino em 2015. No caso da ex-governadora, o gráfico de similitude mostra o seu nome e o seu governo associados a obras, inaugurações, ações positivas. No caso de Dino, seu nome e seu governo estão associados a formas linguísticas que trazem significados negativos relativos à (falta de) segurança pública. O vocabulário mostrado no gráfico é inexistente em relação à infraestrutura não por equilíbrio de cobertura jornalística, mas pelo contrário: o assunto foi pautado de forma a 
apenas mostrar problemas. As ações positivas, como inaugurações e ordens de serviço, foram mantidas fora do noticiário.

$\mathrm{Na}$ amostra analisada, chama atenção o fato de que vários temas relativos à segurança pública e à infraestrutura foram retrancados na editoria de Política. Receberam, portanto, tratamento de assuntos políticos e foram descaracterizados em sua noticiabilidade primária. Tratadas na editoria de política, as pautas ganharam a narratividade inerente ao jornalismo adversário: o governador não conclui tal obra porque não quer, não reduz a criminalidade (antes sob controle nessa mesma narrativa) por incompetência pessoal. A editoria de política vive um superdimensionamento na era pós-Roseana nas páginas de $O$ Estado do Maranhão.

\section{Considerações finais}

O tipo de representação proposta pelo jornal para dois governos diferentes oscila entre o estado-ficção e o estado-problema. De um lado, há a tentativa de construir uma narrativa positiva das ações do governo, como ente abstrato, e da governadora Roseana Sarney, como protagonista, durante o ano de 2014. Em que pesem a crise na segurança pública e os problemas de infraestrutura do Maranhão, o jornal usa esses fatos como uma espécie de alavanca para publicizar promessas de ação - estas sempre positivas e comemoradas como conquistas. Por outro lado, o ano de 2015 registra nas chamadas de capa uma mudança de paradigma jornalístico - sai a narrativa laudatória, entra o jornalismo adversário, um cão de guarda com interesses políticos definidos. Os problemas do Maranhão, antes completamente ignorados ou minimizados, passam a ser estampados diariamente na primeira página, inclusive com recurso a textoseditoriais na capa.

Se antes havia uma diferenciação retórica que atribuía os problemas que o jornalismo de OEMA não podia esconder ao ente abstrato "governo" e as virtudes à ação pessoal da governadora Roseana Sarney, em 2015 as ações positivas foram minimizadas e tanto o abstrato "governo" quanto o personalizável governador Flávio Dino passaram a ser identificados na narrativa como agentes das notícias negativas. A análise quantitativa mostrou uma face do jornalismo adversário praticado por OEMA: a produção em série de notícias negativas relacionadas ao governo e ao governador. O discurso por trás dos números apresentados é muito claro: no Maranhão de agora nada dá certo, nada funciona, regredimos de um patamar que, anteriormente, o jornal descrevia como bom.

A análise do conteúdo mostrou outra face desse jornalismo adversário: a articulação entre palavras e ações que criaram duas representações distintas 
sobre os personagens centrais do discurso sobre o Maranhão em dois momentos diferentes. De um lado, Roseana Sarney. Ligada ao empreendedorismo, a exgovernadora soa nas páginas de seu jornal como alguém sempre em campo, sempre em ação, à frente dos problemas (como ilustra a cobertura sobre reuniões acerca da crise da segurança pública), preocupada em legar ao sucessor um estado pleno de infraestrutura. De outro, Flávio Dino. Não há cobertura sobre inaugurações de seu governo. O governador soa como alguém incapaz de resolver aquele que foi eleito o maior problema do Maranhão a partir de $1^{\circ} \mathrm{de}$ janeiro: a segurança pública.

Éinteressantea escolha da segurança pública como o tema a ser batido pelo jornal: afinal, é preciso manter a coerência em seu discurso e poupar, pelo menos em um primeiro momento, os problemas de infraestrutura. Se o jornal passou o ano de 2014 afirmando que inaugurações foram feitas e obras importantes foram realizadas para sanar problemas existentes, seria uma desconstrução de seu próprio discurso afirmar, em 2015, que o estado está abandonado nesse setor. A segurança pública, por seu turno, é mais conjunturalmente discursável: fácil apresentar jornalisticamente como o setor em que o governador não acertou a mão. A ação pessoal em algo que se deteriora de forma rápida é mais fácil de ser imputada. E isso reforça a própria representação geral do jornal sobre os dois personagens: em 2014, os acertos dizem respeito à ação pessoal de Roseana; erros, ação do ente abstrato "governo"; em 2015, erros são tanto imputáveis ao ente abstrato "governo" quanto ao sujeito "governador". Se o Maranhão não está dando certo em 2015, a responsabilidade tem nome e sobrenome: Flávio Dino.

\section{REFERÊNCIAS}

ALSINA, Miguel Rodrigo. La Construción de la Noticia. Barcelona: Paidós, 1996.

COUTO, Carlos Agostinho de Almeida. Estado, mídia e oligarquia: poder público e meios de comunicação como suporte de um projeto político para o Maranhão. São Luís: EDUFMA, 2009.

COOK, Timothy. Governing with the news: the news media as a political institution. 2 ed. Chicago: Chicago Press, 2005.

ESSER, Frank, STRÖMBÄCK, Jesper. Mediatization of politics: understanding the transformation of Western democracies. Hampshire: Palgrave Macmillan, 2014. DOI: https://doi.org/10.1057/9781137275844.

FAIRCLOUGH, Norman. Discurso e mudança social. Brasília: Editora UNB, 2001. 
FAIRCLOUGH, Norman. Media discourse. New York: St Martin's Press, 1995.

GANS, Herbert. Deciding what's news: a study of CBS Evening News, NBC Nightly News, Newsweek and Time. New York: Vintage Books, 1980.

GENRO FILHO, A. O segredo da pirâmide - Para uma teoria marxista do jornalismo. Porto Alegre: Tchê, 1987.

GRABER, Doris A.; MACQUAIL, Denis; NORRIS, Pippa. The politics of the news, the news of the politics. 2 ed. Washington: CQ Press, 2008.

GRAMSCI, Antonio. Cadernos do cárcere. Vol. 2. 4 ed. Rio de Janeiro: Civilização Brasileira, 2006.

GUAZINA, Liziane Soares. Jornalismo em busca da credibilidade: a cobertura adversária do Jornal Nacional no escândalo do Mensalão. 2011. 256 F. Tese (Doutorado em Comunicação Social) - Faculdade de Comunicação, UNB, Brasília, 2011.

LATTMAN-WELTMAN, Fernando, CHAGAS, Viktor. Mercado futuro: a economia política da (re)partidarização da imprensa no Brasil. In: Dados - Revista de Ciências Sociais. Rio de Janeiro, vol. 59, n. 2, p. 323-354, 2016.

MIGUEL, Luís Felipe, BIROLI, Flávia. A produção da imparcialidade: a construção do discurso universal a partir da perspectiva jornalística. Revista Brasileira de Ciências Sociais: Rio de Janeiro, vol. 25, n. 73, 2010.

MIGUEL, Luís Felipe. Política e mídia no Brasil: episódios da história recente. Brasília: Plano, 2002.

SCHUDSON, Michael. Discovering the news: a social history of american newspapers. New York: Basic Books Inc., 1978. DOI: https://doi.org/10.7208/ chicago/9780226026688.001.0001.

SOUSA, Jorge Pedro. Teorias da notícia e do jornalismo. Chapecó: Argos, 2002.

SPARROW, Bartholomew $\mathrm{H}$. Uncertain guardians: the news media as a political institution. Baltimore: The Johns Hopkins University Press, 1999.

THOMPSON, John. Brookshire. O escândalo político: poder e visibilidade na era da mídia. Petrópolis: Vozes, 2002.

TRAQUINA, Nelson (org). Teorias do jornalismo: porque as notícias são como são. Vol. 1. Florianópolis: Insular, 2004.

TUCHMAN, Gaye. La Producción de la noticia: estudio sobre la construcción de la realidad. Barcelona: Gili, 1983. 
WOLF, Eric. Envisioning power: ideologies of dominance and crisis. Berkeley, University of California Press, 1999.

WOLF, Eric. Antropologia e poder. Contribuições de Eric Wolf. Editora UNB, Imprensa Oficial do Estado de São Paulo, Editoria Unicamp, 2003.

Recebido em: 25/4/2017

Aceito em: 8/8/2017

Dados da autora:

Li-Chang Shuen Cristina Silva Sousa | lichangshuen@gmail.com

Doutora, professora Adjunta do Departamento de Comunicação Social da Universidade Federal do

Maranhão. Departamento de Comunicação Social da Universidade Federal do Maranhão

Avenida dos Portugueses, 1.966 - Bacanga

65065-545 - São Luís (MA) - Brasil 